\title{
SIMULATION OF THE HEAT LASER OF THE SELECTIVE LASER SINTERING PROCESS OF THE POLYAMIDE12
}

\author{
Hanane YAAGOUBI ${ }^{1}$, Hamid ABOUCHADI ${ }^{1}$, Mourad TAHA JANAN ${ }^{1}$
}

${ }^{1}$ Laboratory of Applied Mechanics and Technologies (LAMAT), ENSET, STIS Research Center Mohammed V University, Rabat, morocco, hanane.yaagoubi@um5s.net.ma.

\begin{abstract}
Laser sintering sintering is one of the most widely used 3D printing technologies, in which it transforms 3D models into authentic parts with generally excellent workmanship, the test today is to ensure the unmatched nature of the item produced, therefore hypothetically to understand and predict the thermal history in this process, the thermal models must be exact and fair, In this article, the consideration will be focused on the different models of heat flux diffusion, in the bibliography, some formulas Numbers that describe the transport of the heat source out of the powder bed have been found. A comparison between its laser source models will be established. The re-modeling takes place in MATLAB using the parameters of polyamide12.
\end{abstract}

\section{INTRODUCTION}

Selective Laser Sintering (SLS) is one of the 3D printing technologies that enables the design of complex three dimensions parts with layers of nylon12 powder material heated by a $\mathrm{CO}_{2}$ laser that generates a gaussian distribution of heat flux on the polyamide upper of powder bed. The surface thermal source models are the most used compared to volumetric source models, in this context, we will compare four models of surface heat source cited in the literature by [1] [2][3][4], one of which is experimentally validated by the author [1]. these functions relate several parameters, for example, the laser power, the spot radius, the radial distance, the absorption rate, ... etc., so understanding the effects of different laser parameters on the difference of the partition of the heat source is very important [5-12].

In the thermal equation which describes the heat transfer in the polyamide 12 powder bed, there are three phenomena in the heat transfer process

- conduction;

- convection;

- radiation;

$$
\frac{\partial T}{\partial t}=\frac{K_{e}}{C_{p} \rho}\left(\frac{\partial T^{2}}{\partial x^{2}}+\frac{\partial T^{2}}{\partial y^{2}}+\frac{\partial T^{2}}{\partial z^{2}}\right)+Q_{v}
$$

Where: $\mathrm{T}=\mathrm{T}(\mathrm{x}, \mathrm{y}, \mathrm{z}, \mathrm{t})$ is the temperature on the $(\mathrm{x}, \mathrm{y}, \mathrm{z})$ point;

$\lambda$ - Thermal conductivity, in $[\mathrm{W} / \mathrm{mK}]$;

$\rho$ - Mass density, in $[\mathrm{kg} / \mathrm{m} 3)]$;

$\mathrm{Cp}$ - Specific heat, in $[\mathrm{J} / \mathrm{kgK}]$;

$\mathrm{Q}$ - heat source distribution, in [W/m3].

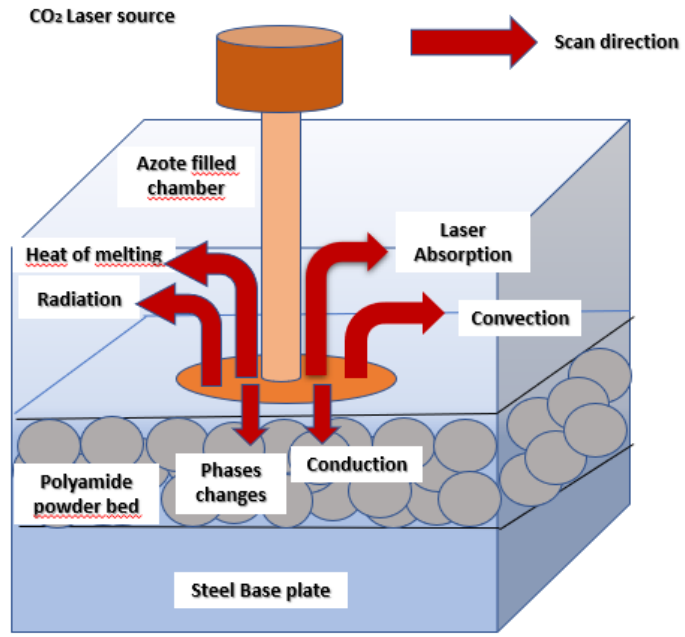

Fig.1. Thermal effects of laser interaction with nylon 12 powder during SLS process

\section{2. heAt SOURCE MOdelling IN SLS PROCESSES}

As the laser passes over the surface, it melts the powder material to form a solid layer of polyamide 12 . The use of the laser flux which is a gaussian beam whose development of the amplitude profile of the electric field, the transverse magnetic power as a function of the spatial propagation is relative to a gaussian function, for example a gauss-Hermite function.

This laser flux is essential for liquefying the nylon 12 powder bed, whose hot vitality required for sintering, heating obtained by transforming the dynamic vitality of the electrons into a hot vitality [9]. 


\section{SURFACE DISTRIBUTED HEAT FLUX MODELS}

- The first heat source model

The model of the distribution of the heat flux chosen by the author [2] is described in the following mathematical form:

$$
\mathrm{Q}(\mathrm{x}, \mathrm{y})=\frac{2 \mathrm{P}}{\pi \mathrm{r}^{2}} \exp \frac{-2\left(\mathrm{x}^{2}+\mathrm{y}^{2}\right)}{\mathrm{r}^{2}}
$$

Hence, $\mathrm{Q}$ is the applied flow thermal, $\mathrm{P}$ is the laser power, and $\mathrm{r}$ is the laser spot radius on the top of the layer, $x^{2}+y^{2}$ is the radial distance from the center axis of the beam. The laser parameters are listed in Table 1 .

- The second heat source model

The model of the partition of the thermal flow chosen by the author $[3,4]$ is described in the following mathematical form:

$$
\mathrm{Q}(\mathrm{x}, \mathrm{y})=\frac{2 \mathrm{AP}}{\pi \mathrm{r}^{2}} \exp \frac{-2\left(\mathrm{x}^{2}+\mathrm{y}^{2}\right)}{\mathrm{r}^{2}}
$$

where $\mathrm{Q}$ is the applied heat flux, A is the energy absorption coefficient, $\mathrm{A}$ is the absorption rate of the powder bed from nylon 12 to laser $\mathrm{P}$ the value taken from figure 4 [6] and $\mathrm{r}$ is the laser spot radius on the top surface., $x^{2}+y^{2}$ is the distance between the center axis of the spot laser and the parameters are listed in Table 1.

- The third heat source model

The model of the the partition of the thermal flow chosen by the author [5] is described in the following mathematical form:

$$
\mathrm{Q}(\mathrm{x}, \mathrm{y})=\frac{4.55 \mathrm{P}}{\pi \mathrm{r}^{2}} \exp \left(4.55 \frac{\mathrm{x}^{2}+\mathrm{y}^{2}}{\mathrm{r}^{2}}\right)
$$

Hence, Q is the applied heat flux, $\mathrm{P}$ is the laser power, and $\mathrm{r}$ is the rayon laser spot, on the upper layer, $x^{2}+y^{2}$ the distance between the center axis of the spot laser and the parameters are listed in Table 1.

- The fourth heat source model

The model of the the partition of the thermal flow chosen by the author [1] is described in the following mathematical form and it's experimentally validated:

$\mathrm{Q}(\mathrm{x}, \mathrm{y})=\mathrm{k} \cdot \mathrm{n} \frac{\mathrm{P}}{\pi \mathrm{r}^{2}} \exp \left(-\mathrm{n} \frac{\mathrm{x}^{2}+\mathrm{y}^{2}}{\mathrm{r}^{2}}\right)$

Hence, $\mathrm{Q}=$ surface heat flux $\left(\mathrm{W} / \mathrm{m}^{2}\right), \mathrm{n}=4$, rlaser $(\mathrm{m})=$ laser radius at $1 / \mathrm{e}^{2}, \mathrm{P} 0(\mathrm{~W})=$ average laser power, $\mathrm{K}=$ adjustable coefficient $<1$ integrating reflectivity $\mathrm{R}$ and Mie diffusion $\mathrm{D}$ factors $(\mathrm{K}=(1-\mathrm{R}) \cdot(1-\mathrm{D}))$ of the laser through the powder layer, $x^{2}+y^{2}$ is the distance between the center axis of the spot laser and the parameters are listed in Table 1.

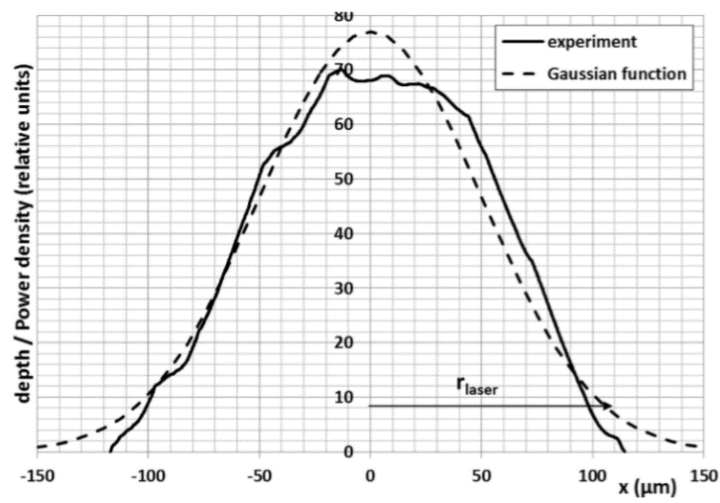

Fig.2. Static $\mathrm{CO}_{2}$ laser impact at $\mathrm{P} 0=27.5 \mathrm{~W}$ laser power

on a thick polymer foil. Identification of the rayon of the spot laser and comparison of the experimentally determined fused profile (2D profilometer) with an analytical quasi-Gaussian partition [1].

Table 1. Laser Parameters of the process SLS and thermo-physical properties of nylon 12 for laser $\mathrm{CO} 2$ $(\lambda=10.6 \mu \mathrm{m})$

\begin{tabular}{|c|c|c|c|c|}
\hline $\begin{array}{c}\text { Laser } \\
\text { parameter } \\
\text { propermal }\end{array}$ & Full name & Value & Unit & $\begin{array}{c}\text { Referenc } \\
\text { e }\end{array}$ \\
\hline $\mathbf{A}$ & $\begin{array}{l}\text { The } \\
\text { absorption rate } \\
\text { of the powder } \\
\text { bed from } \\
\text { nylon12 to } \\
\text { laser P }\end{array}$ & 0.95 & $\%$ & {$[6]$} \\
\hline $\mathbf{P}$ & $\begin{array}{c}\text { The laser } \\
\text { power }\end{array}$ & 30 & $\mathrm{w}$ & - \\
\hline $\mathbf{r}$ & The spot laser & 0.6 & $\mathrm{~mm}$ & - \\
\hline $\mathbf{n}$ & - & 4 & - & {$[1]$} \\
\hline $\mathbf{k}$ & $\begin{array}{c}\text { Adjustable } \\
\text { coefficient }\end{array}$ & 0.5 & - & {$[1]$} \\
\hline $\mathbf{Q}$ & $\begin{array}{c}\text { Heat source } \\
\text { function }\end{array}$ & - & & - \\
\hline
\end{tabular}

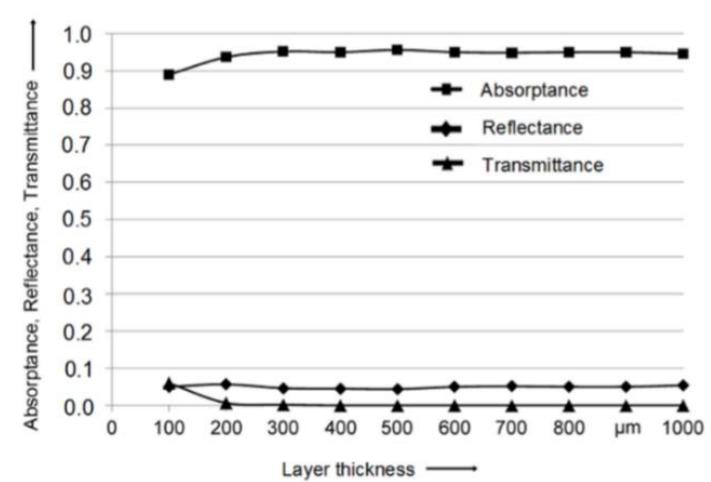


Fig.3. Optical material characteristics of polyamide 12 for different layer thicknesses [6].

\section{RESULT AND DISCUSSION}

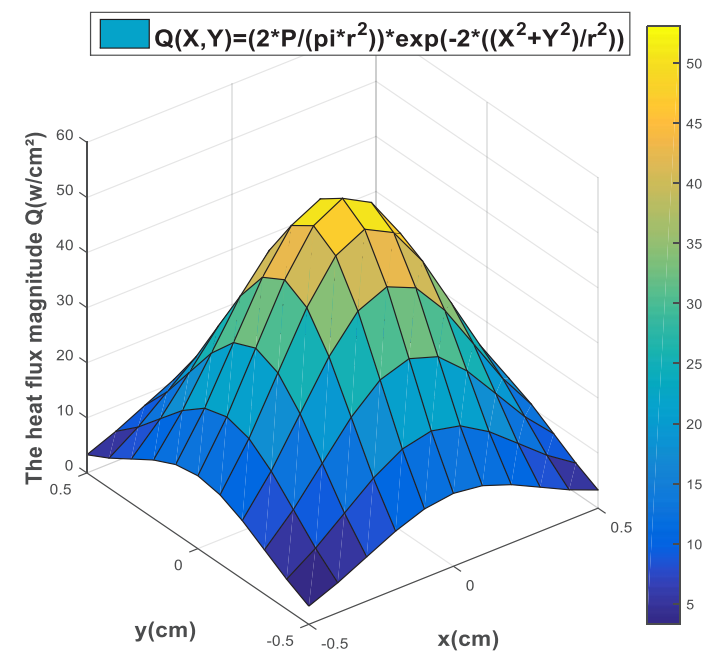

Fig.4. Distribution of the laser beam on the powder bed of nylon powder 12 - the first model heat source

The figure 4 shows the gaussian distribution of the heat flow under the same conditions listed in table 1, with this first model, the magnitude of the heat flux increases to $32 \mathrm{w} / \mathrm{cm}^{2}$, respectively at the surface powder bed.

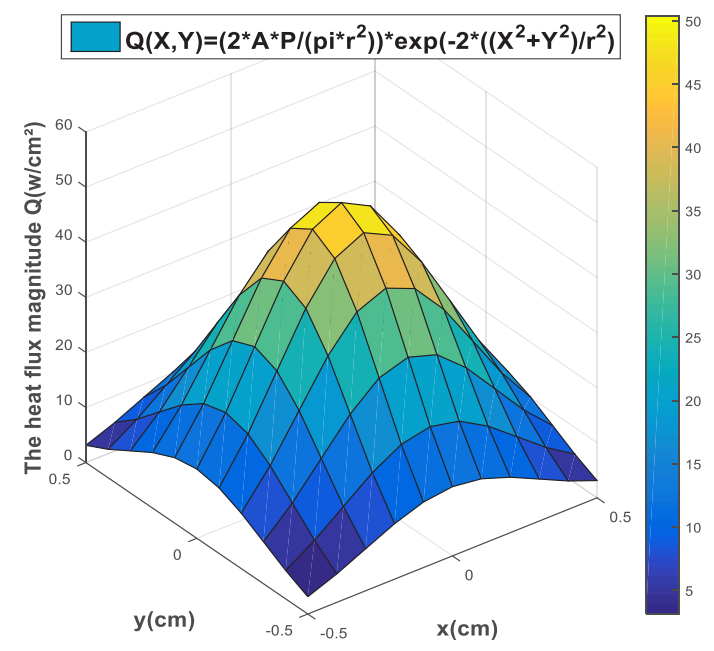

Fig.5. Distribution of the laser beam on the powder bed of nylon powder 12- The second model heat source

The figure 5 shows the gaussian distribution of the heat flow under the same conditions listed in table 1, with this first model, the magnitude of the heat flux increases to $30 \mathrm{w} / \mathrm{cm}^{2}$, respectively at the surface powder bed.

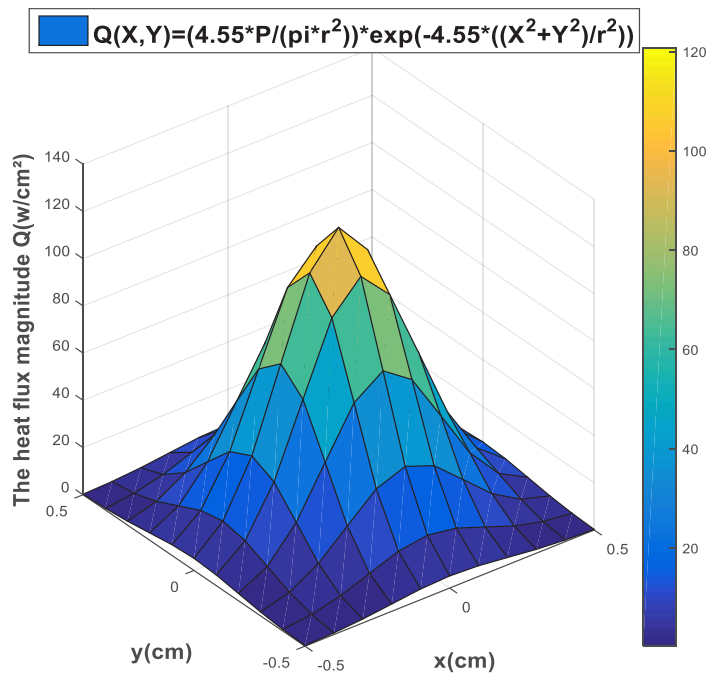

Fig.6. Distribution of the laser beam on the powder bed of nylon powder 12 - the third model heat source

The figure 6 shows the gaussian distribution of the heat flow under the same conditions listed in table 1, with this first model, the magnitude of the heat flux increases to $70 \mathrm{w} / \mathrm{cm}^{2}$, respectively at the surface powder bed.

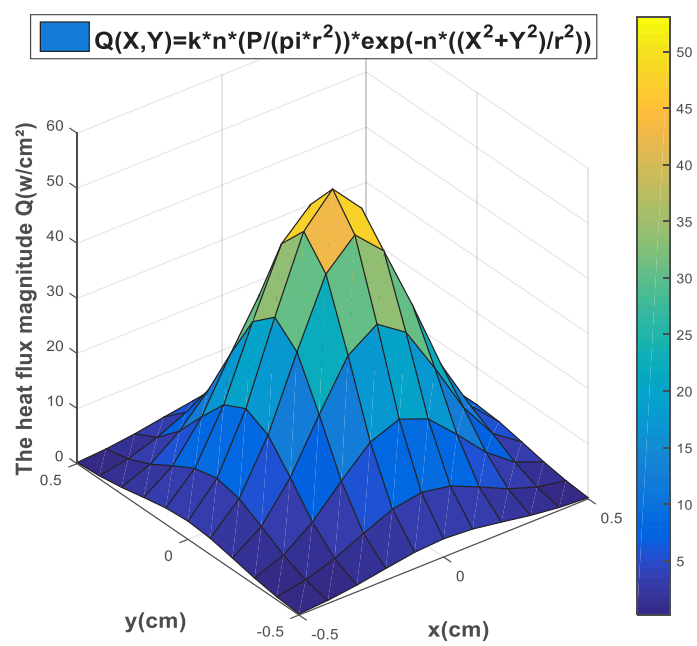

Fig.7. Distribution of the laser beam on the powder bed of nylon powder $12-$ the fourth model heat source

The figure 7 exposes the gaussian partition of the heat flow under the same conditions listed in table 1, with this first model, the magnitude of the heat flux increases to $32 \mathrm{w} / \mathrm{cm}^{2}$, respectively at the surface powder bed. 


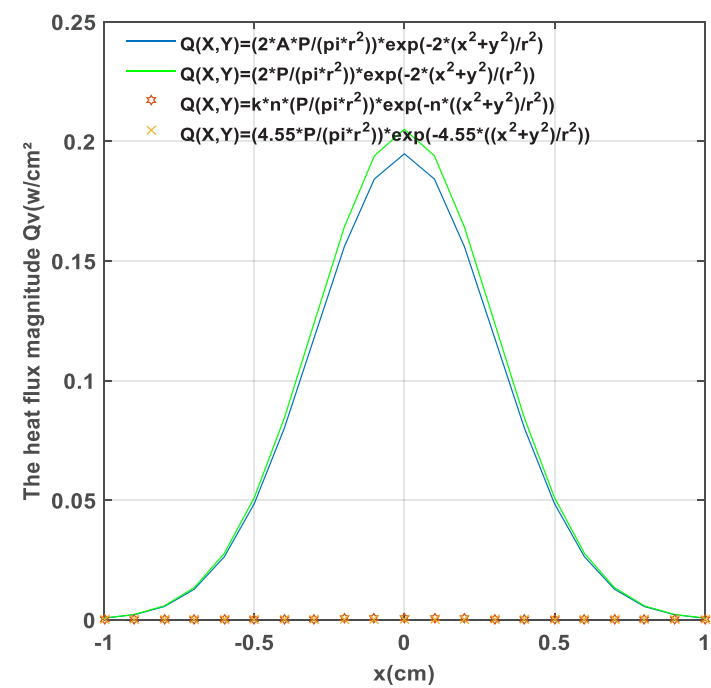

Fig.8. Comparison between four-surface distributed heat source models.

The figure 8 shows a comparison between a four-surface distributed heat source models, which all this models are given under the same conditions listed in table 1, the first model and second model, are identical, the magnitude of the heat flux increases to $0,17 \mathrm{w} / \mathrm{cm}^{2}$, and for the second model, the magnitude of the heat flux model increases to $0,22 \mathrm{w} / \mathrm{cm}^{2}$, and the two first models show a little large values compared to the other two models. The difference is about 0.2 and the both models are very close.

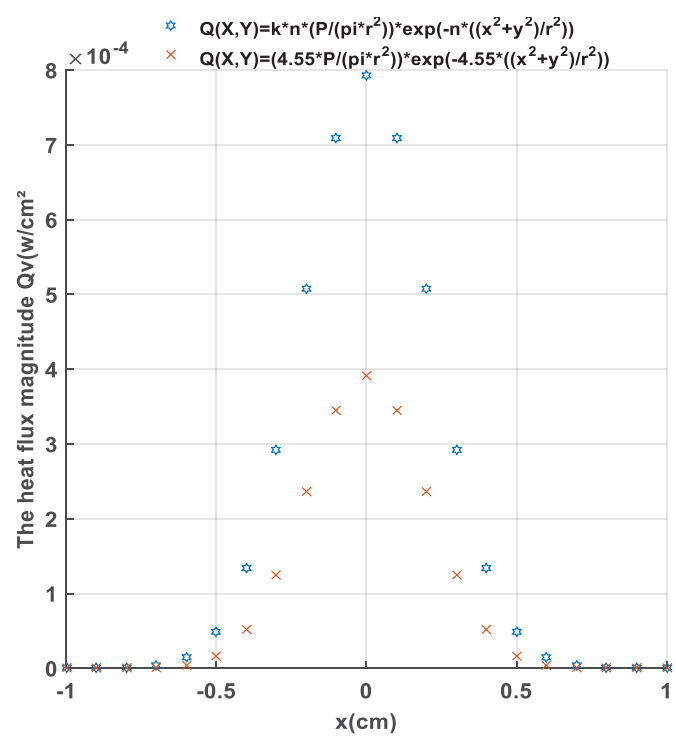

Fig.9. Comparison between a third and fourth surface distributed heat source models.

The figure 9 shows clearly a value of magnitude of the heat flux, the first model was increased to $4 \mathrm{e}-4$ and the second model was increased to $8 \mathrm{e}-4$, , the difference between them is 0.0004 , which it shows that the model is very correct also and more accurate compared to other models.

\section{CONCLUSION}

In this paper, a comparison of some important models of the surface heat source distribution for the modelization of the laser flux penetration on nylon12 powder bed fusion additive manufacturing bed during the selective laser sintering process has presented, the impact of this research focuses on the improvement of another accurate and correct thermal simulation model for the SLS and to discover the influence of adding other characteristics of the process, the main conclusions are summarized as follows:

- A third model seem correct and show a good result compared to fourth model validated to the experimental result found by the author [1], the error is less than 0.0004 the first and second models are very close, but their result is a little larger than the other models compared to the experimental result by the author [1], the error is around 0.18-0.21.

in general, all these errors are too small and we have confirmed the model approved experimentally by the author [1] as well as the theoretical third model of the author [5] which is very close.

\section{References}

[1] Yann ROUCHAUSSE, Patrice PEYRE, Denis DEFAUCHY, Gilles REGNIER - Experimental and numerical analysis of the selective laser sintering (SLS) of PA12 and PEKK semicrystalline polymers - Journal Of Materials Processing Technology - Vol. 225, p.326-336 - 2015

[2] Roberts, I. A., Wang, C. J., Esterlein, R., Stanford, M., and Mynors, D. J., 2009, “A Three-Dimensional Finite Element Analysis of the Temperature Field during Laser Melting of Metal Powders in Additive Layer Manufacturing," Int. J. Mach. Tools Manuf., 49(12-13), pp. 916-923. R. Nicole, "Title of paper with only first word capitalized," J. Name Stand. Abbrev., in press.

[3] Dong, L., Makradi, A., Ahzi, S., and Remond, Y., 2009, "ThreeDimensional Transient Finite Element Analysis of the Selective Laser Sintering Process," J. Mater. Process. Technol., 209(2), pp. 700-706.

[4] Hussein, A., Hao, L., Yan, C., and Everson, R., 2013, "Finite Element Simulation of the Temperature and Stress Fields in Single Layers Built Without- Support in Selective Laser Melting," Mater. Des., 52(0), pp. 638-647.

[5]Patil, R. B., and Yadava, V., 2007, "Finite Element Analysis of Temperature Distribution in Single Metallic Powder Layer During Metal Laser Sintering," Int. J. Mach. Tools Manuf., 47(78), pp. 1069-1080. M. Young, The Technical Writer's Handbook. Mill Valley, CA: University Science, 1989.

[6]Tobias Laumera-c, Katrin Wudyb,e, Maximilian Drexlerb,c,e, Philipp Amenda,b, Stephan Rotha,b, Dietmar Drummerb,e, Michael Schmidta-d , 2014. Fundamental investigation of selective laser sintering of polymers for additive manufacture, blz Bayerisches Laserzentrum GmbH, Erlangen, Germany.

[7] Kai Zeng, Deepankar Pal, Brent Stucker , A review of thermal analysis methods in Laser Sintering and Selective Laser Melting , January 2012 , Department of Industrial Engineering, University of Louisville, Louisville, KY 40292.

[8] David C. Deisenroth, Ramin Moradi, Amir H. Shooshtari, Farah Singer Avram Bar-Cohen \& Michael Ohadi 2017, Review of heat exchangers enabled by polymer and polymer composite additive manufacturing,

[9] G. N. Levy, 2010, "The role and future of the laser technology in the additive manufacturing environment," Physics Procedia, 5, 65-80. 
[10] N. Guo, M. C. Leu, 2013 “ Additive manufacturing: technology, applications and research needs," Front. Mech. Eng., 8(3), 215243.

[11] Manfred Schmid, Antonio Amado, and Konrad Wegener 2015; Polymer powders for selective laser sintering (SLS) Manfred Schmid, Antonio

Amado, and Konrad Wegener , Citation: 1664, 160009 ; doi: $10.1063 / 1.4918516$

[12] Manfred Schmida and Antonio Amado 2014, Materials perspective of polymers for additive manufacturing with selective laser sintering, irpd Institute for Rapid Product Development, CH-9014 St. Gallen, Switzerland Konrad Wegener Department of Mechanical and Process Engineering, Swiss Institute of Technology, CH-8093 Zürich, Switzerland. 